\title{
Sexual health of male cardiac patients - present status and expectations of patients with coronary heart disease
}

Dariusz Kałka1,2, Łukasz Karpiński ${ }^{2,3}$, Jana Gebala², Lesław Rusiecki ${ }^{1}$ Anna Biełous-Wilk ${ }^{1}$ Ewa S. Krauz ${ }^{4}$, Magdalena Piłot' ${ }^{5}$, Krzysztof Womperski ${ }^{6}$, Małgorzata Rusiecka ${ }^{7}$, Witold Pilecki ${ }^{1}$

\author{
${ }^{1}$ Cardiosexology Unit, Department of Pathophysiology, Medical University of Wroclaw, \\ Wroclaw, Poland \\ ${ }^{2}$ Center of Men's Health, Wroclaw, Poland \\ ${ }^{3}$ Center of Cardiac Prevention and Rehabilitation CREATOR, Wroclaw, Poland \\ ${ }^{4}$ Department of Cardiac Rehabilitation, Lower Silesian Heart Diseases Centre \\ "Medinet", Wroclaw, Poland \\ ${ }^{5}$ Department of Cardiac Rehabilitation, Centre of Cardiac Rehabilitation and Cardiac \\ Prevention, Glucholazy, Poland \\ ${ }^{6}$ Department of Cardiac Rehabilitation, Hospital of the Ministry of Interior, Glucholazy, \\ Poland \\ ${ }^{7}$ Department of Oncology and Gynaecologic Oncology, Medical University of Wroclaw, \\ Wroclaw, Poland
}

Submitted: 2 March 2015

Accepted: 17 April 2015

Arch Med Sci 2017; 13, 2: 302-310

DOI: https://doi.org/10.5114/aoms.2017.65332

Copyright @ 2017 Termedia \& Banach

\section{Abstract}

Introduction: Due to the pathogenetic association between erectile disorders and cardiovascular diseases, cardiologists consult many patients with erectile dysfunction (ED). The aim of the study was to evaluate sexual function in patients with coronary heart disease (CHD) and the use of sexual knowledge in cardiology practice, both current use and that expected by patients.

Material and methods: One thousand one hundred and thirty-six patients (average age: $60.73 \pm 9.20$ ) underwent a dedicated survey which encompassed demographic data and the presence of modifiable ED risk factors. The presence of ED was assessed using the International Index of Erectile Function (IIEF-5) Questionnaire.

Results: Sexual problems were discussed by cardiologists with 45 (3.96\%) patients. The frequency of initiating the topic was significantly associated with the respondents' education level $(p=0.0031)$; however, it was not associated with the patients' age, duration of CHD, presence of ED, or modifiable risk factors. Four hundred and sixteen (36.62\%) respondents indicated that they expect their cardiologist to take an interest in their ED. Nine hundred and twenty-six (81.51\%) patients claimed good sexual function to be important or very important to them. Attitude to sexual function was significantly associated with age $(p<0.0001)$, duration of CHD $(p=0.0018)$, education $(p=0.0011)$, presence of ED $(p=0.0041)$, diabetes $(p=0.0283)$ and hyperlipidaemia $(p=0.0014)$.

Conclusions: The low frequency with which cardiologists initiate the topic of ED is in contrast to the expectations of patients with CHD. The majority of these patients regard good sexual maintenance as an important part of their life.

Key words: cardiologist, erectile dysfunction, coronary heart disease, cardiosexology, risk factors, cardiac rehabilitation.

\author{
Corresponding author: \\ Dariusz Katka \\ Cardiosexology Unit \\ Department of \\ Pathophysiology \\ Medical University of Wroclaw \\ K. Marcinkowskiego St 1 \\ 50-368 Wrocław, Poland \\ Phone: +48 717840060 \\ E-mail: dariusz.kalka@gmail. \\ com
}




\section{Introduction}

According to the definition of the National Health Institute Consensus Panel on Impotence, erectile dysfunction (ED) is characterised by a permanent inability to attain and/or maintain erection of the penis sufficient to permit satisfactory sexual intercourse [1]. The pathophysiological mechanism of ED may have a psychological, neurological, hormonal, vascular, cavernosal, or combined character [2]. However, in recent years particular attention has been paid to the coexistence of ED and cardiovascular diseases. The National Institutes of Health Consensus Panel on Impotence stated that "most of the medical disorders associated with ED appear to affect the arterial system". They especially affect men over 50 years of age. In this group, up to $40 \%$ of ED cases are associated with vascular disorders [1]. This stems from the pathophysiology of these two disorders. Both originate from many common risk factors affecting the endothelium which cause the progression of atherosclerosis and the beginnings of ED [3-6]. The association between these disorders translates into a significant percentage of cardiac patients who also suffer from ED. A cardiologist's competence and skills may significantly improve the quality of life of such patients [7].

The aim of the study was to assess the importance of good sexual function to patients with CHD and the current use and patient-expected use of sexual knowledge in cardiology practice.

\section{Material and methods}

A group of 1136 patients from five centres was analysed. All patients were being treated for coronary heart disease (CHD) and were undergoing cardiac rehabilitation. All subjects gave informed consent for participation in the study.

Patients underwent a dedicated survey which included closed-ended questions regarding demographic data, presence of modifiable risk factors of ED (smoking, hypertension, hyperlipidaemia, diabetes, excessive body mass, low physical activity), and presence of ED symptoms. Moreover, the survey encompassed questions regarding initiation of the topic of ED by cardiologists, respondents' expectations about ED-initiated conversations by cardiologists, and the importance of good sexual function to the patient. An analysis of the intensity of physical activity was carried out using a questionnaire modelled on the Framingham questionnaire [8]. Duration of physical activity was estimated with an accuracy of up to one quarter of an hour. The minimum level of physical activity appropriate in prevention of cardiovascular diseases was set at the value of energy expenditure equal to $1000 \mathrm{kcal}$ per week [9].
The presence of ED was assessed using a shortened version of the IIEF-5 [10]. Sexual intercourse during which a patient was not able to have and maintain an erection suitable for intercourse after treatment with phosphodiesterase type 5 (PDE-5) inhibitors was evaluated. Patients with ED occurring because of surgical treatment of prostatic hyperplasia or prostate cancer were excluded from the study.

The study was conducted after obtaining approval from the Commission of Bioethics at Wroclaw Medical University (KB - 433/2010) in the framework of the PREVANDRO project and served as an introduction to targeted cardiosexology education. Educational activities were performed using a Power Point presentation, printed materials (leaflets, IIEF-5 questionnaire), and an internet website. The education was carried out in the years 2012-2015 and has covered, to date, 5237 patients.

\section{Statistical analysis}

For comparisons between groups of variables with a normal distribution, Student's t-test for independent variables was used. Linear relationships between those variables were examined, and Pearson's correlation coefficient was calculated. For comparison between groups of variables with a distribution other than normal, the Mann-Whitney $U$ test was used. In those cases, relationships were analysed using Pearson's correlation coefficient. In simple comparisons of dichotomous variables, the $\chi^{2}$ test (with Yates' correction for continuity for $2 \times 2$ contingency tables) was used. In analysis of the influence of many factors on respondents' knowledge, logistic regression was used. The significance of a particular predictor's influence was expressed by the probability level associated with the Wald $\chi^{2}$ distribution. The calculated odds ratio described the strength of influence of the examined parameter on the final result.

In all performed tests, a probability $(p)$ value less than 0.05 was considered statistically significant. Statistical analysis was carried out using Statistica software v 10 (StatSoft, Oklahoma, USA).

\section{Results}

One thousand one hundred and thirty-six questionnaires were analysed. Clinical characteristics of the study group are presented in Table I. In the analysed group of patients, cardiologists initiated a discussion about ED with 45 patients $(3.96 \%$ of the study group). Eight of these patients (0.07\%) had already started on therapy with PDE-5 inhibitors. The average age of patients who were asked about ED by cardiologists was not significantly different 
Table I. Characteristics of patients with coronary heart disease

\begin{tabular}{|c|c|}
\hline Parameter & Study group \\
\hline Number of studied subjects & 1136 \\
\hline Age [years] & $60.73 \pm 9.20$ \\
\hline \multicolumn{2}{|l|}{ Place of living: } \\
\hline Rural area & $319(28.08 \%)$ \\
\hline City & $817(71.92 \%)$ \\
\hline \multicolumn{2}{|l|}{ Education level: } \\
\hline University degree & $219(19.28 \%)$ \\
\hline Pre-university & $429(37.76 \%)$ \\
\hline Lower vocational & $382(33.63 \%)$ \\
\hline Primary & $106(9.33 \%)$ \\
\hline $\begin{array}{l}\text { Myocardial infarction in medical } \\
\text { history }\end{array}$ & $848(74.64 \%)$ \\
\hline $\mathrm{BMI}\left[\mathrm{kg} / \mathrm{m}^{2}\right]$ & $27.43 \pm 3.24$ \\
\hline $\begin{array}{l}\text { Average intensity of leisure time } \\
\text { physical activity [kcal/week] }(n=883)\end{array}$ & $502.20 \pm 400.05$ \\
\hline $\begin{array}{l}\text { Erectile dysfunction of the penis }{ }^{\star * * *} \\
(n=881)\end{array}$ & $698(79.23 \%)$ \\
\hline Severe dysfunction (score $5-7$ ) & $102(11.58 \%)$ \\
\hline $\begin{array}{l}\text { Moderate-to-mild dysfunction } \\
\text { (score } 8-11)\end{array}$ & $113(12.82 \%)$ \\
\hline Moderate dysfunction (score 12-16) & $233(26.45 \%)$ \\
\hline Mild dysfunction (score 17-21) & $250(28.38 \%)$ \\
\hline PTCA & $546(48.06 \%)$ \\
\hline CABG & $359(31.60 \%)$ \\
\hline PTCA and CABG & $157(13.82 \%)$ \\
\hline \multicolumn{2}{|l|}{ Risk factors of IHD: } \\
\hline Hypertension & $726(63.91 \%)$ \\
\hline Type II diabetes & $270(23.77 \%)$ \\
\hline Dyslipidaemia & $630(55.46 \%)$ \\
\hline Cigarette smoking & $774(68.13 \%)$ \\
\hline Number of pack-years of smoking & $34.08 \pm 20.30$ \\
\hline Active cigarette smoking $(n=774)$ & $130(16.80 \%)$ \\
\hline $\begin{array}{l}\text { Number of pack-years of active } \\
\text { smoking }\end{array}$ & $36.40 \pm 18.57$ \\
\hline Overweight* & $655(57.66 \%)$ \\
\hline Obesity $^{* *}$ & $228(20.07 \%)$ \\
\hline $\begin{array}{l}\text { Insufficient intensity of leisure } \\
\text { time physical activity*** }(n=883)\end{array}$ & $812(91.96 \%)$ \\
\hline \multicolumn{2}{|c|}{$\begin{array}{l}\text { n-number of subjects, BMI-body mass index, PTCA-percutaneous } \\
\text { transluminal coronary angioplasty, CABG - coronary artery bypass } \\
\text { graft, IHD - ischaemic heart disease, IIEF - International Index } \\
\text { of Erectile Function, }{ }^{*} 25 \leq B M I<29.9 \mathrm{~kg} / \mathrm{m}^{2} \text {, }{ }^{* *} B M I \geq 30.0 \mathrm{~kg} / \mathrm{m}^{2} \text {, } \\
{ }^{* * *}<1000 \mathrm{kcal} / \text { week, }{ }^{* * *} / I E F-5 \leq 21 .\end{array}$} \\
\hline
\end{tabular}

from the age of those who were not asked (61.08 \pm 8.92 vs. $60.71 \pm 9.21 ; p=0.7895)$. The average time from diagnosis of $\mathrm{CHD}$ in the group of patients asked about ED by cardiologists did not differ significantly from patients who were not asked (4.40 \pm 4.48 years vs. $3.89 \pm 5.98$ years; $p=0.5766$ ).

Distribution of education level and presence of modifiable cardiovascular disease (CVD) risk factors of ED among survey respondents is presented in Table II.

Frequency of cardiologists addressing the issue of sexual function is correlated with a patient's education and does not depend on the presence of modifiable CVD risk factors. Moreover, the total analysis of all CVD risk factors including the influence of age and level of education did not reveal significantly greater frequency of addressing the topic of ED when analysed together with any combination of risk factors, age, or level of education of respondents.

In the analysed group of patients, 488 (42.96\%) people claimed good sexual function to be very important to them, while 438 (38.56\%) claimed it to be important. One hundred and fifty-four $(13.56 \%)$ claimed it to be neither important or unimportant, and $56(4.93 \%)$ responders claimed sexual function to be unimportant to them. Attitude to sexual function was negatively correlated with age. Sexual performance was very important for patients with an average age of $58.45 \pm 8.65$ years old, important $61 \pm 8.81$; neither important nor unimportant $63.34 \pm 9.38$, and unimportant $67.52 \pm 10.38$. The correlation coefficient was $-0.236(p<0.0001)$. This indicates that sexual function is much more important for younger men.

Attitude to good sexual function was significantly correlated with the time from diagnosis of CHD $(R=-0.0924 ; p=0.0018)$, the level of education $(R=-0.0962 ; p=0.0011)$, and the presence of ED. Attitude to good sexual function, by presence of ED and modifiable CVD risk factors, is presented in Table III.

Among individually assessed modifiable CVD risk factors, attitude to sexual function was significantly associated with the presence of diabetes and hyperlipidaemia. The presence of hyperlipidaemia significantly increased the importance placed on sexual function, while the presence of diabetes decreased it. The presence of the remaining risk factors was not significantly related to attitude regarding sexual function.

Combined analysis of all modifiable risk factors additionally includes influence of age and level of education of the respondents. It reveals a statistically significant correlation between attitude to good sexual function and cigarette smoking in patients with vocational education $(p=0.0292)$. A significant correlation between attitude to good 
Table II. Distribution of education level and presence of modifiable risk factors of cardiovascular disease ( $n, \%)$ among respondents who discussed and did not discuss ED problems with a cardiologist

\begin{tabular}{|c|c|c|c|c|}
\hline \multirow[t]{2}{*}{ Variable } & \multicolumn{2}{|c|}{ Conversation about ED (+) } & \multicolumn{2}{|c|}{ Conversation about ED (-) } \\
\hline & Number & Percentage & Number & Percentage \\
\hline University degree & 17 & 8.1 & 192 & 91.9 \\
\hline Pre-university education & 15 & 3.8 & 384 & 96.2 \\
\hline Lower vocational education & 12 & 3.3 & 349 & 96.7 \\
\hline Primary education & 1 & 1.0 & 99 & 99.0 \\
\hline$P$-value & \multicolumn{4}{|c|}{0.0031} \\
\hline Hypertension (+) & 34 & 4.68 & 692 & 95.32 \\
\hline Hypertension (-) & 11 & 2.68 & 399 & 97.32 \\
\hline$P$-value & \multicolumn{4}{|c|}{0.13318} \\
\hline Hyperlipidaemia (+) & 31 & 4.92 & 599 & 95.08 \\
\hline Hyperlipidaemia (-) & 14 & 2.77 & 492 & 97.23 \\
\hline$P$-value & \multicolumn{4}{|c|}{0.08974} \\
\hline Diabetes (+) & 13 & 4.81 & 257 & 95.19 \\
\hline Diabetes (-) & 32 & 3.70 & 834 & 96.30 \\
\hline$P$-value & \multicolumn{4}{|c|}{0.51900} \\
\hline Cigarette smoking $(+)$ & 28 & 3.62 & 746 & 96.38 \\
\hline Cigarette smoking (-) & 17 & 4.70 & 345 & 95.30 \\
\hline$P$-value & \multicolumn{4}{|c|}{0.48068} \\
\hline Obese and overweight (+) & 36 & 4.08 & 847 & 95.92 \\
\hline Obese and overweight (-) & 9 & 3.56 & 244 & 96.44 \\
\hline$P$-value & \multicolumn{4}{|c|}{0.84865} \\
\hline Leisure time physical activity (+) & 37 & 4.56 & 775 & 95.44 \\
\hline Leisure time physical activity (-) & 2 & 2.82 & 69 & 97.18 \\
\hline$P$-value & \multicolumn{4}{|c|}{0.70171} \\
\hline
\end{tabular}

sexual function and health-promoting physical activity was found in patients having a university degree $(p=0.01710)$.

In the analysed group of patients, 228 (20.07\%) of them did not want to discuss the issue of their sexual function with a doctor, 279 (24.56\%) patients had no opinion, 213 (18.75\%) patients wanted these issues to be addressed by a doctor other than a cardiologist, and 414 (36.62\%) patients indicated that they would like their cardiologist to be interested in the presence of ED.

The average age of patients who expected their cardiologist to show interest in their sexual health does not differ significantly from the average age of patients who did not expect their doctor to take interest $(60.43 \pm 8.80$ vs. $60.89 \pm 9.42 ; p=0.4200)$.

The average time from diagnosis of CHD in the group of patients expecting a cardiologist's inter- est in their sexual health is not significantly different from the average time from diagnosis of CHD in the group of patients who do not expect a cardiologist's interest in their sexual problems (3.90 \pm 6.48 years vs. $3.91 \pm 5.60$ years; $p=0.9764$ ).

The level of education of the respondents is significantly associated with patients' expectations of the interest in their sexual health from cardiologists.

Table IV shows patient expectation distribution by the presence of erectile disorders, education level, and the presence of modifiable CVD risk factors.

In the total study group, the presence of ED does not significantly influence the expectation of the topic of sexual function being addressed by cardiologists. Including age and education level of respondents in the analysis reveals the fact that 
D. Kałka, Ł. Karpiński, J. Gebala, L. Rusiecki, A. Biełous-Wilk, E.S. Krauz, M. Piłot, K. Womperski, M. Rusiecka, W. Pilecki

Table III. Importance of sexual function $(n, \%)$ in relation to the presence of ED and modifiable risk factors of CVD

\begin{tabular}{|c|c|c|c|c|c|c|c|c|}
\hline \multirow[t]{2}{*}{ Variable } & \multicolumn{2}{|c|}{ Very important } & \multicolumn{2}{|c|}{ Important } & \multicolumn{2}{|c|}{$\begin{array}{l}\text { Neither important } \\
\text { nor unimportant }\end{array}$} & \multicolumn{2}{|c|}{ Not important } \\
\hline & Number & Percentage & Number & Percentage & Number & Percentage & Number & Percentage \\
\hline ED $(+)$ & 284 & 40.69 & 289 & 41.4 & 85 & 12.18 & 40 & 5.73 \\
\hline ED (-) & 97 & 53.01 & 60 & 32.79 & 23 & 12.57 & 3 & 1.64 \\
\hline$P$-value & \multicolumn{8}{|c|}{0.0041} \\
\hline DIA (+) & 105 & 38.89 & 103 & 38.15 & 40 & 14.81 & 22 & 8.15 \\
\hline DIA (-) & 383 & 44.23 & 335 & 38.68 & 114 & 13.16 & 34 & 3.93 \\
\hline$P$-value & \multicolumn{8}{|c|}{0.0283} \\
\hline $\mathrm{HL}(+)$ & 290 & 46.03 & 248 & 39.37 & 61 & 9.68 & 31 & 4.92 \\
\hline $\mathrm{HL}(-)$ & 198 & 39.13 & 190 & 37.55 & 93 & 18.38 & 25 & 4.94 \\
\hline$P$-value & \multicolumn{8}{|c|}{0.0014} \\
\hline SMO (+) & 343 & 44.32 & 303 & 39.15 & 84 & 10.85 & 44 & 5.68 \\
\hline SMO (-) & 145 & 40.06 & 135 & 37.29 & 70 & 19.34 & 12 & 3.31 \\
\hline$P$-value & \multicolumn{8}{|c|}{0.068310} \\
\hline $\mathrm{HT}(+)$ & 315 & 43.39 & 291 & 40.08 & 80 & 11.02 & 40 & 5.51 \\
\hline HT (-) & 173 & 42.20 & 147 & 35.85 & 74 & 18.05 & 16 & 3.90 \\
\hline$P$-value & \multicolumn{8}{|c|}{0.290286} \\
\hline LTPA (+) & 350 & 43.10 & 319 & 39.29 & 104 & 12.81 & 39 & 4.80 \\
\hline LTPA (-) & 32 & 45.07 & 30 & 42.25 & 5 & 7.04 & 4 & 5.63 \\
\hline$P$-value & \multicolumn{8}{|c|}{0.540855} \\
\hline OB $(+)$ & 100 & 39.53 & 104 & 41.11 & 38 & 15.02 & 11 & 4.35 \\
\hline OB (-) & 388 & 43.94 & 334 & 37.83 & 116 & 13.14 & 45 & 5.10 \\
\hline$P$-value & \multicolumn{8}{|c|}{0.289057} \\
\hline
\end{tabular}

expectations for the topic of sexual function to be addressed by cardiologists is significantly associated with the presence of ED (OR = 1.7307; $95 \% \mathrm{Cl}: 1.1405-2.6264)$ in younger $(\mathrm{OR}=0.9810$; 95\% Cl: 0.9639-0.9984) and better-educated patients (OR $=1.2675 ; 95 \% \mathrm{Cl}: 1.0771-1.4916)$.

Among individually assessed modifiable CVD risk factors, expectations of the topic of sexual function being addressed by cardiologists is significantly associated with the presence of hypertension and hyperlipidaemia in patients. The odds ratio of the expectation of a cardiologist's interest in sexual health of a patient suffering from hypertension is $1.525(95 \% \mathrm{Cl}: 1.179-1.973)$ and for hyperlipidaemia 1.457 (95\% Cl: 1.140-1863). The presence of the remaining CVD risk factors is not significantly associated with expectations of cardiologists' interest in the presence of ED. A combined analysis of the modifiable CVD risk factors including the additional influence of age and education level of respondents indicates a greater frequency of expectation of the topic of ED being addressed by cardiologists in the group of better-educated respondents (OR $=1.3927$; $95 \% \mathrm{Cl}: 1.2102-1.6027)$, cigarette smokers (OR = $1.3148 ; 95 \% \mathrm{Cl}: 1.0061-1.7180)$, and patients suffering from hypertension $(\mathrm{OR}=1.4942 ; 95 \% \mathrm{Cl}$ : 1.1515-1.9389).

\section{Discussion}

Results of epidemiological studies conducted until now clearly indicate an association between ED and CHD [11]. The knowledge of this association, its role in the pathogenesis of both of these disorders, and the risk factors which are important for inducing atherosclerosis indicate the great usefulness of ED assessment, as ED is regarded as an early marker of atheromatosis in a wide population of men $[12,13]$. Interest in the presence 
Table IV. Expectations for addressing the topic of erectile disorders $(n, \%)$ in relation to the presence of erectile disorders, education level, and the presence of modifiable CVD risk factors

\begin{tabular}{|c|c|c|c|c|}
\hline \multirow[t]{2}{*}{ Variable } & \multicolumn{2}{|c|}{$\begin{array}{c}\text { Expectation of cardiologist-initiated } \\
\text { conversation }(+)\end{array}$} & \multicolumn{2}{|c|}{$\begin{array}{c}\text { Expectation of cardiologist-initiated } \\
\text { conversation }(-)\end{array}$} \\
\hline & Number & Percentage & Number & Percentage \\
\hline Erectile dysfunction (+) & 261 & 37.39 & 437 & 62.61 \\
\hline Erectile dysfunction (-) & 56 & 30.60 & 127 & 69.40 \\
\hline$P$-value & \multicolumn{4}{|c|}{0.10580} \\
\hline University degree & 108 & 49.32 & 111 & 50.68 \\
\hline Pre-university education & 156 & 36.36 & 273 & 63.64 \\
\hline Lower vocational education & 126 & 32.98 & 256 & 67.02 \\
\hline Primary education & 26 & 24.53 & 80 & 75.47 \\
\hline$P$-value & \multicolumn{4}{|c|}{0.000006} \\
\hline Hypertension (+) & 291 & 40.08 & 435 & 59.92 \\
\hline Hypertension (-) & 125 & 30.49 & 285 & 69.51 \\
\hline$P$-value & \multicolumn{4}{|c|}{0.0016} \\
\hline Hyperlipidaemia (+) & 255 & 40.48 & 375 & 59.52 \\
\hline Hyperlipidaemia (-) & 161 & 31.82 & 345 & 68.18 \\
\hline$P$-value & \multicolumn{4}{|c|}{0.0032} \\
\hline Diabetes (+) & 102 & 37.78 & 168 & 62.22 \\
\hline Diabetes (-) & 314 & 36.26 & 552 & 63.74 \\
\hline$P$-value & \multicolumn{4}{|c|}{0.70391} \\
\hline Cigarette smoking $(+)$ & 297 & 38.37 & 477 & 61.63 \\
\hline Cigarette smoking (-) & 119 & 32.87 & 243 & 67.13 \\
\hline$P$-value & \multicolumn{4}{|c|}{0.08424} \\
\hline Obese and overweight (+) & 335 & 37.94 & 548 & 62.06 \\
\hline Obese and overweight (-) & 81 & 32.02 & 172 & 67.98 \\
\hline$P$-value & \multicolumn{4}{|c|}{0.09893} \\
\hline Physical activity (+) & 295 & 36.33 & 517 & 63.67 \\
\hline Physical activity (-) & 22 & 30.99 & 49 & 69.01 \\
\hline$P$-value & \multicolumn{4}{|c|}{0.44060} \\
\hline
\end{tabular}

of ED and, consequently, its prevention and pharmacological treatment offered to patients with previously diagnosed CHD results in an increase of their quality of life [14-16]. Therefore, undoubtedly sexual knowledge is useful in cardiology practice. Questions are raised as to what part of this knowledge is currently used in everyday cardiology practices, how patients with CHD perceive the importance of good sexual function, and what they expect from cardiologists in the field of sexual health.

In the analysed group of patients with CHD, a cardiologist-initiated conversation about ED was reported in 45 (3.96\%) cases. Similar results were obtained by Bedell et al., who reported that only $3 \%$ of male respondents claimed to be adequately informed about their sexual functioning [17]. Also the analysis performed by Kloner et al. revealed that most of men had not previously discussed the topic with their cardiologist [18]. In the CHARMS study, up to $66 \%$ of the respondents claimed that they had never talked about sexual problems during a medical visit [19]. Similar results of doctors' interest in the sexual function of their patients are reported by the doctors themselves. Nicolai et al., who surveyed 414 cardiolo- 
gists, found that $16 \%$ of them discussed sexual problems during their patients' visits, and as many as $70 \%$ rarely or never advised patients who have suffered a myocardial infarction to resume sexual activity [20]. Only Roth et al., who conducted a telephone survey on a group of 379 specialists, reported that among the cardiologists, 77\% declared personal engagement in managing patients with sexual function disorders. However, as many as $74 \%$ of the doctors underestimated the frequency (as published in the medical literature) of ED in patients in general and among cardiac patients [21]. In the present study only $0.70 \%$ of patients received PDE-5, which is safe and available. This seems to prove a lack of cardiologists' interest in this group of drugs [14].

The basis for ED prevention is the identification of modifiable risk factors of CVD [22]. Considering that none of the analysed risk factors significantly influenced the degree of a cardiologist's interest in sexual function of his patients except for a patient's level of education, it indicates a greater ease of asking well-educated patients about sexual problems, which are regarded as difficult and in timate. Despite the recognised negative influence of age on the risk of ED, in our study, this factor did not significantly determine cardiologists' interest in sexual function of patients with CHD. Duration of CHD treatment translates into multiplicity of cardiology visits and potentially increases opportunities to discuss ED. However, this factor did not significantly impact the frequency of bringing up the topic either.

Perception of sexual function by patients with CHD is important as it influences progress of the disease. In the study group, good sexual function was important or very important for $81.51 \%$ of respondents and unimportant for $4.93 \%$. It was negatively correlated with age, indicating greater interest of younger men in this aspect of life, and significantly positively correlated with the level of education, indicating greater interest of well-educated men in sexual function. The above-mentioned correlation may arise from a greater openness and better knowledge of the importance of intimate life for well-being presented by younger people with a higher level of education. In the CHARMS study, a lack of interest in sex was reported by $10 \%$ of patients [17].

The presence of ED and duration of treatment of CHD are factors which significantly determined the attitude towards sexual function in our study. This indicates greater importance of sexual function for respondents who have been suffering from CHD longer and are affected by ED. In the present study, diabetes and hyperlipidaemia significantly impact the attitude towards sexual function. In hyperlipidaemia, the presence of this disorder increases the importance of sexual func- tion, while the presence of in diabetes negatively influenced the attitude towards sexual function. ED begins in diabetic patients even about 10-15 years earlier than in the general population and limits the possibility of conducting satisfying sexual activity. This fact may lead over time to acceptance of the condition by diabetic patients and may result in less attention to good sexual performance [23]. Patients' expectations from cardiologists seem to be crucial for the treatment of CHD and its comorbidities. In the analysed group, $55.37 \%$ of respondents wished their doctor to show an interest in their sexual function, but the percentage of patients who wanted this issue to be addressed during cardiology visits was already about $18.75 \%$ smaller. Lack of knowledge about associations between ED and CVD in a wide population of patients results in excluding cardiologists from the group of doctors who are able to help the patient when ED occurs.

In the present study the percentage of patients awaiting a cardiologist's advice was much lower than in the study performed by Nicolai et al., where up to $88 \%$ of men declared that they would like to discuss sexual function with their cardiologist and would feel comfortable discussing sexual health. Forty-six percent of them would like to discuss possibilities of improving sexual function with their cardiologist [24]. In Byrne's study, up to $63 \%$ of the respondents wanted these issues to be addressed [19]. The aforesaid results prove a lower level of openness in discussing issues of ED among patients with $\mathrm{CHD}$ from the study group.

In our study, patient expectations related to sexual function are significantly associated with their level of education. The seeming lack of correlation between a patient's expectation of the cardiologist addressing the topic of sexual function and the age of a patient may, despite that lack, imply that all patients should be asked about ED including the elderly. Decreasing sexual function with age may incorrectly classify older patients as less interested in sexual health. This rule, however, should not limit cardiologists' willingness to open a discussion on sexual issues with such patients. Patients' expectations are not influenced by duration of CHD. Length of being treated for CHD should not be considered as a factor limiting a cardiologist's interest in the sexual health of their patients.

Overall, the presence of ED does not influence patients' expectations, despite high interest in sexual health declared in this group. The reason lies in the lack of knowledge of treatment possibilities, and the lack of awareness that sexual problems can be addressed by a cardiologist, who is not generally considered a specialist in sexual health. The presence of ED increases these expectations; however, they are limited to younger and 
better-educated respondents. Greater openness and awareness created by education enable patients to make enquiries and direct expectations to cardiologists, who should actively participate in the struggle for good sexual health in patients suffering from CHD. Hypertension and hyperlipidaemia were linked with higher expectations of cardiologists' interest in patients' sexual health. In hyperlipidaemia, this may result from frequent presentation of the negative influence of elevated cholesterol concentrations on sexual function highlighted in health campaigns. In hypertension, patients' concern arises from possible side-effects of CHD treatments described in drug leaflets, particularly second-generation $\beta$-adrenoceptor antagonists [12].

Other CVD risk factors occurring in a considerable percentage of patients did not significantly determine patients' expectations of cardiologists. This confirms the fact that the level of knowledge of the harmful influence of modifiable CVD risk factors on sexual health in men in a wide population of patients is still unsatisfactory. The abovesaid fact is also highlighted in other works [25].

The results presented in our analysis are in line with Jackson's findings on incomplete use of knowledge of the association between ED and CHD in everyday cardiology practice [26]. This problem related to both patients who were treated in cardiology departments for the first manifestation of CHD and those who suffered from chronic disease and were under long-term cardiac supervision. A cardiologist is a competent specialist who can assess individual exercise tolerance, estimate the risk arising from sexual activity, and recommend proper pharmacologic treatment for ED. However, such competencies were applied only in regard to a small percentage of patients [14]. Low engagement of cardiologists and low use of their knowledge of ED is an important finding of this study. This fact should act as a stimulus to broaden cardiologists' education, aiming to improve care of the sexual health of patients with CHD. Much attention is also needed to broaden cardiac sexual education directed at a wider population of men.

In conclusion, cardiologists rarely address the presence of modifiable risk factors as well as sexual function problems, which are in contrast with the expectations of patients with CHD. Application of the knowledge of the association between modifiable CVD risk factors and ED in medical practice is insufficient. It requires broadening their education on a variety of aspects of cardiosexology.

The study revealed a relatively small number of patients $(n=45)$ who talked about their sexual health with a cardiologist in comparison to the total number of studied patients. Therefore further research is required. The small group of patients with CHD treated with PDE-5 inhibitors limited further analyses on their application patterns.

\section{Acknowledgments}

The authors would like to thank Mr Krzysztof Głąbek, whose work enabled performing analyses on such a large group of patients.

The study was conducted in the Cardiosexology Unit, Department of Pathophysiology, Wrocław Medical University. The data were collected in five centres of cardiac rehabilitation.

\section{Conflict of interest}

The authors declare no conflict of interest.

\section{References}

1. NIH Consensus Development Panel of Impotence. JAMA 1993; 270: 83-90.

2. Saenz De Tejada I, Angulo J, Cellek S, et al. Pathophysiology of erectile dysfunction. J Sex Med 2005; 2: 26-39.

3. Lyngdorf P, Hemmingsen L. Epidemiology of erectile dysfunction and its risk factors: a practice-based study in Denmark. Int J Impot Res 2004; 16: 105-11.

4. Kaminetsky J. Epidemiology and pathophysiology of male sexual dysfunction. Int J Impot Res 2008; 20: 3-10.

5. Derby CA, Mohr BA, Goldstein I, et al. Modifiable risk factors and erectile dysfunction: can lifestyle changes modify risk. Urology 2000; 56: 302-6.

6. Lai HM, Aronow WS, Mercando AD, et al. Risk factor reduction in progression of angiographic coronary artery disease. Arch Med Sci 2012; 8: 444-8.

7. Jackson G, Nehra A, Miner M, et al. The assessment of vascular risk in men with erectile dysfunction: the role of the cardiologist and general physician. Int J Clin Pract 2013; 67: 1163-72.

8. Arsenault BJ, Rana JS, Lemieux I, et al. Physical activity, the Framingham risk score and risk of coronary heart disease in men and women of the EPIC-Norfolk study. Atherosclerosis 2010; 209: 261-5.

9. Drygas W, Jegier A, Kostka H, et al. Long-term effects of different physical activity levels on coronary risk factors in midle-aged men. Int J Sports Med 2000; 21: 235-41.

10. Rosen RC, Cappelleri JC, Smith MD, et al. Development and evaluation of an abridged, 5-item version of the International Index of Erectile Function (IIEF-5) as a diagnostic tool for erectile dysfunction. J Impot Res 1999; 11: 319-26.

11. Thompson IM, Tangen CM, Goodman PJ, et al. Erectile dysfunction and subsequent cardiovascular disease JAMA 2005; 294: 2996-3002.

12. Green JS, Holden ST, Ingram P, et al. An investigation of erectile dysfunction in Gwent, Wales. BJU International 2001; 88: 551-3.

13. Wełnicki M, Mamcarz A. Is erectile dysfunction an independent risk factor of coronary heart disease or another clinical manifestation of progressive atherosclerosis? Kardiol Pol 2012; 70: 953-7.

14. Nehra A, Jackson G, Miner M, et al. The Princeton III Consensus Recommendations for the management of erectile dysfunction and cardiovascular disease. Mayo Clin Proc 2012; 87: 766-78. 
15. O'Donnell AB, Araujo AB, McKinlay JB. The health of normally aging men: the Massachusetts Male Aging Study (1987-2004). Exp Gerontol 2004; 39: 975-84.

16. Hodges LD, Kirby M, Solanki J, et al. The temporal relationship between erectile dysfunction and cardiovascular disease. Int J Clin Pract 2007; 61: 2019-25.

17. Bedell SE, Duperval M, Goldberg R. Cardiologists' discussions about sexuality with patients with chronic coronary artery disease. Am Heart J 2002; 144: 239-42.

18. Kloner RA, Mullin SH, Shook T, et al. Erectile dysfunction in the cardiac patient: how common and should we treat? J Urol 2003; 170: S46-50.

19. Byrne M, Doherty S, Murphy AW, et al. The CHARMS Study: cardiac patients' experiences of sexual problems following cardiac rehabilitation. Eur J Cardiovasc Nurs 2013; 12: 558-66.

20. Nicolai MP, Both S, Liem SS, et al. Discussing sexual function in the cardiology practice. Clin Res Cardiol 2013; 102: 329-36.

21. Roth A, Malov N, Behar S; Israel Heart Society for the Sexual Activity Cardiological Survey. Sexual activity cardiological survey on members of the Israel Heart Society. Int J Clin Pract 2003; 57: 285-8.

22. Feldman HA, Goldstein I, Hatzichristo DG, et al. Impotence and its medical and psychosocial correlates: results of the Massachusetts Male Aging Study. J Urol 1994; 151: 54-61.

23. Eardley I. The incidence, prevalence and natural history of erectile dysfunction. Sex Med Rev 2013; 1: 13-16.

24. Nicolai MPJ, van Bavel J, Somsen GA, et al. Erectile dysfunction in the cardiology practice - a patients' perspective. Am Heart J 2014; 167: 178-85.

25. Baumgartner MK, Hermanns T, Cohen A, et al. Patients' knowledge about risk factors for erectile dysfunction is poor. J Sex Med 2008; 5: 2399-404.

26. Jackson G. Erectile dysfunction and coronary disease: evaluating the link. Maturitas 2012; 72: 263-4. 